\title{
About the Artist: Kalisolaite 'Uhila
}

W hile on a 2018 residency at the Youkobo Art Space in Tokyo, Tongan-New Zealand performance artist Kalisolaite 'Uhila connected with other Tongans living there, undertaking research into their experiences of Asian culture and the nature of time-how its use and contours may change according to where we might be located, the spaces we inhabit, and the people with whom we are sharing those spaces. Researching the interaction between bodies and ideas in and through time informs both philosophical and material aspects of his work

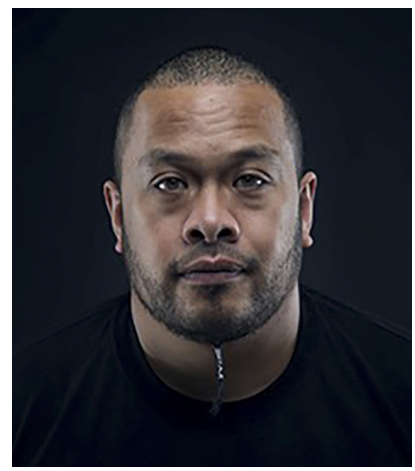

Рното ву PAтti Solomona Tyrell as a performance artist. Audiences responding to the sensory and visual impact of his work are drawn to contemplate its metaphorical references to Pacific Islander experiences in historical and geopolitical contexts. Similarly, a personal focus on relationships with others, and life outside the time and space of performance, provides 'Uhila with a meditative still-point that enables him to endure the emotional and physical demands of site-specific, durational practices.

After living in a shipping container with a pig for a week, inhabiting the streets of Auckland for three months for a project about homelessness, performing on the roof of a gallery to bemused spectators in adjacent high-rise buildings and the street below, and since "cooking" himself in an umu, 'Uhila has attracted a loyal following, received numerous awards, and been in demand for regional and international exhibitions and residencies in New Zealand, Germany, Canada, Japan, Tonga, and the Cook Islands. In 20I6, he completed his master's of performance and media arts at Auckland University of Technology (АUT) with first-class honors. He is represented by Michael Lett in New Zealand (http://michaellett.com) and in 2019 is a featured artist in the second Honolulu Biennial (https://www .honolulubiennial.org).

MOANA NEPIA

The art featured in this issue can be viewed in full color in the online versions. 


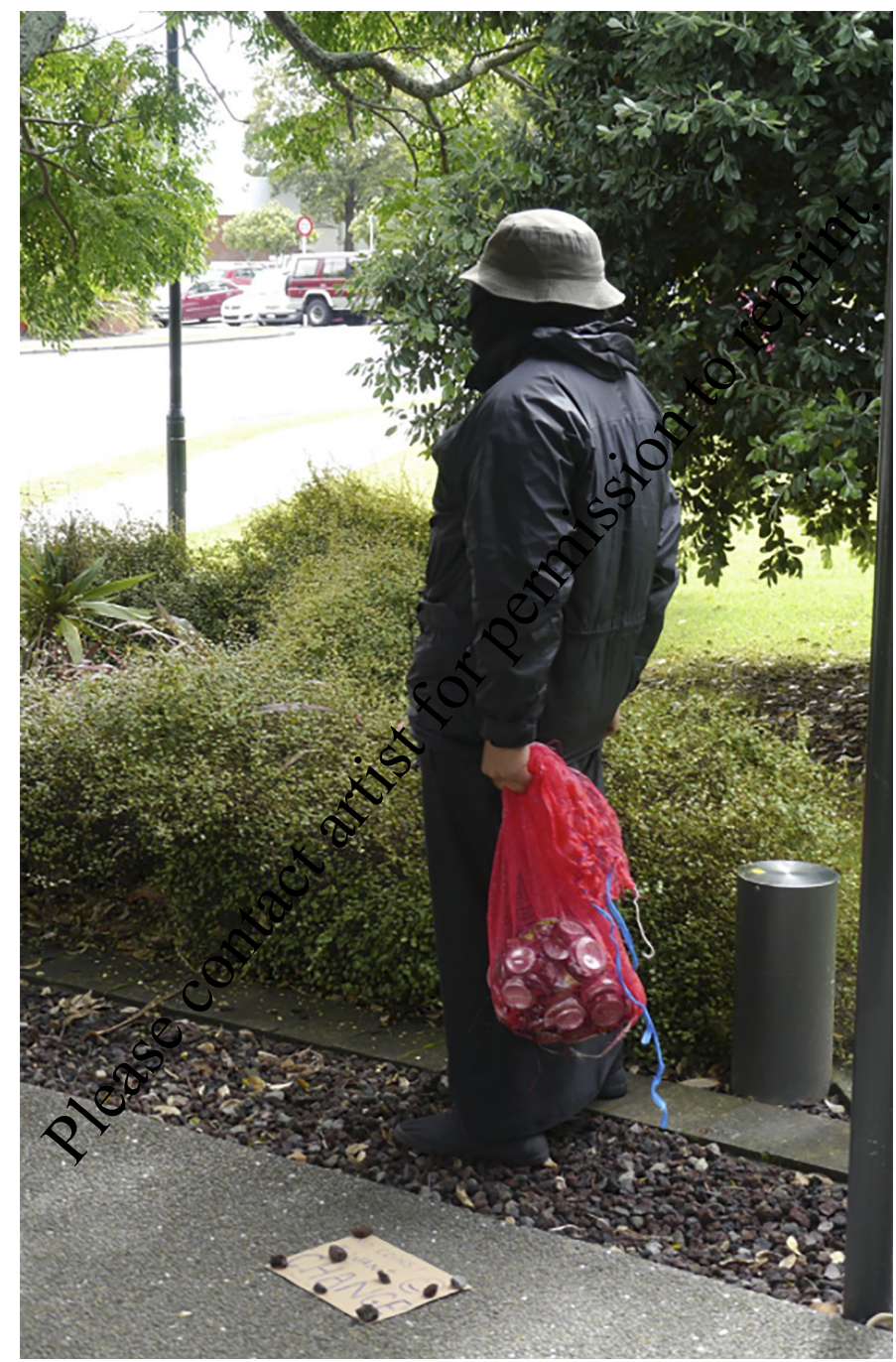

Mo'ui tukuhausia, by Kalisolaite 'Uhila, 20I 2 and 2014 .

Performance, Te Tuhi Centre for the Arts, 2012;

The Walters Prize, Auckland Art Gallery, 2014.

Photo by Bruce Phillips, courtesy of the artist and Michael Lett.

In an effort to draw attention to increasing levels of homelessness in Auckland, one of the most expensive cities in the world, 'Uhila took up a weeklong residency in the grounds of Te Tuhi Centre for the Arts in 2012 and on the city's streets for three months in 20I4. Mo "ui tukuhausia, meaning "to be absolutely stranded," "left friendless," or "destitute," also draws attention to the emotional experiences and disproportionate overrepresentation of Pacific Islanders facing homelessness in other Pacific centers, such as Honolulu, Saipan, Papeete, Suva, Port Moresby, or Sydney. 


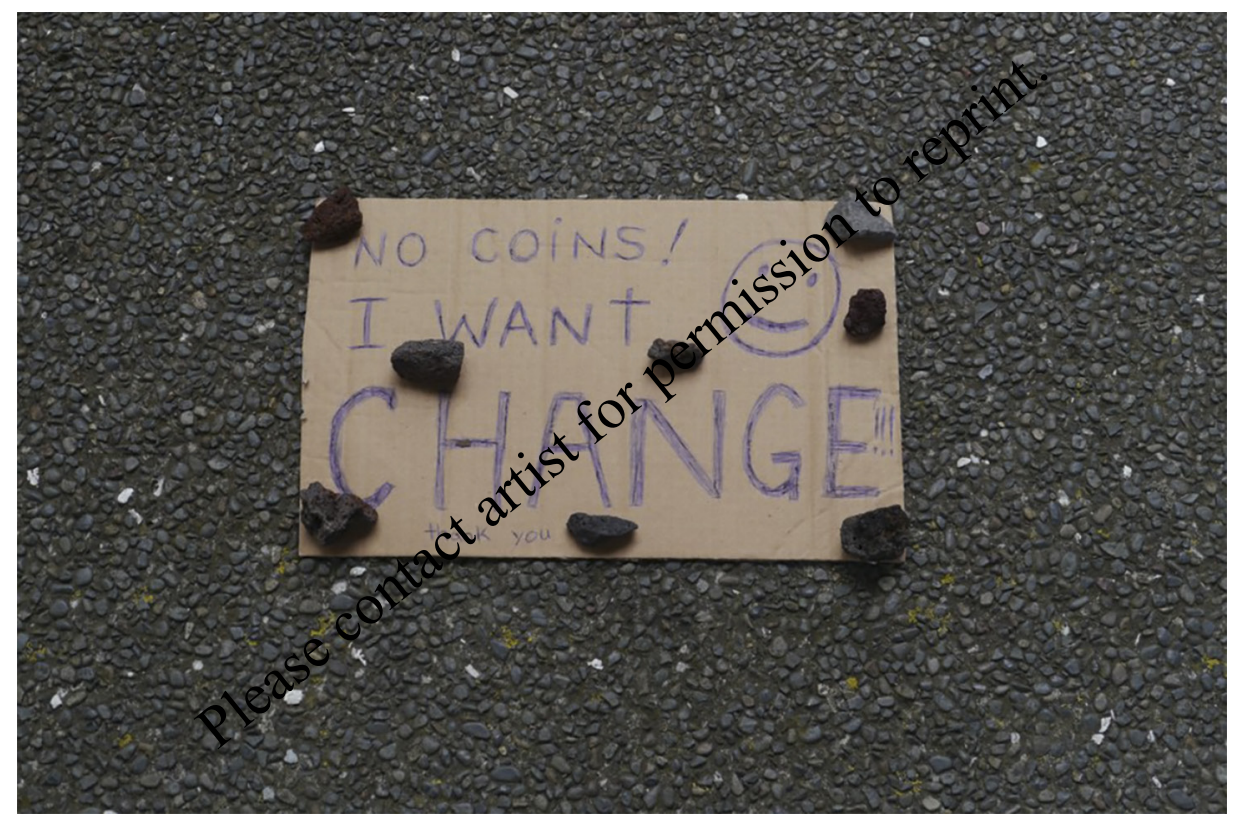

Mo'ui tukuhausia, by Kalisolaite 'Uhila, 2012.

From the exhibition What do you mean, we?, Te Tuhi Centre for the Arts, 3 March-6 May 2012.

Photo by Bruce Phillips, courtesy of the artist and Michael Lett.

'Uhila's message on this cardboard placard for Mo'ui tukuhausia is a call to action that recognizes the transformative political power of the personal gesture. It also prompts us to think beyond small, random acts of charity and toward sustainable solutions for homelessness that will bring lasting change. Attacking issues of climate change and sea-level rising, poverty, pollution, human rights abuses, and the scourge of lifestyle-related diseases in the Pacific requires similar emphasis on raising personal and collective levels of consciousness, shifting focus away from the self-centered excesses of neoliberalism and isolationist thinking, reaffirming universal rights, and values of kindness and respect, multilateral thinking, and collaboration. 


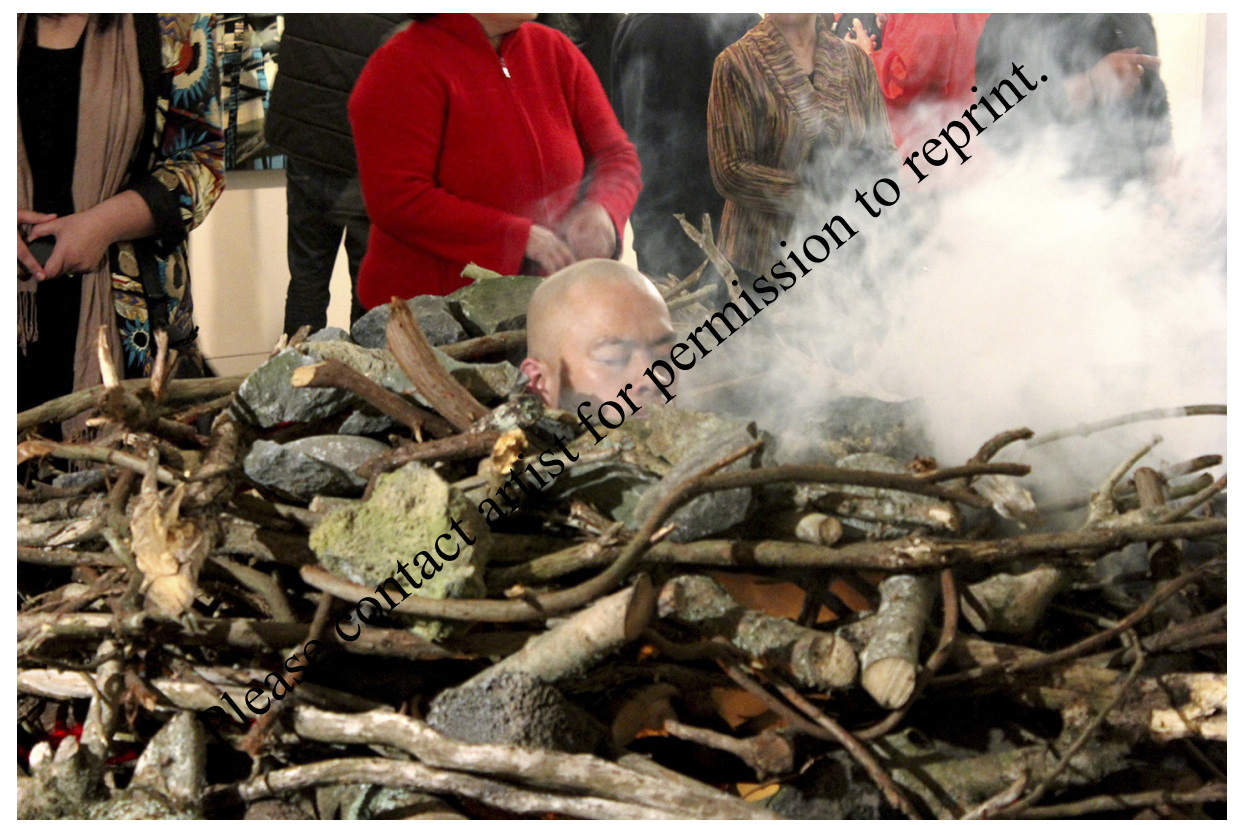

Umu Tangata, by Kalisolaite 'Uhila, 2013.

Performance, volcanic rocks, wood, smoke machine, lights.

Mangere Arts Centre, Auckland.

Photo courtesy of the artist and Michael Lett.

While preparing for Umu Tangata, 'Uhila was thinking about his role as an artist—sacrificing himself as "an offering" for his people, his country, and his work. In order to sustain the physical ordeal of this eight-hour performance, he described "energizing himself" outside of the immediate situation by focusing his thoughts elsewhere, on external situations and his family. In this way, Umu Tangata also acts as a metaphor for enduring distress and discomfort, including the challenges of sustaining a livelihood as a professional artist. 'Uhila worked nights in a brewery to support his family before relocating to Tonga after feeling his creative work was not fully achieving what he wanted. He moved back to Auckland (where he continues to live) after receiving his nomination for New Zealand's most prestigious contemporary art award, the Walters Prize, in 2014. 


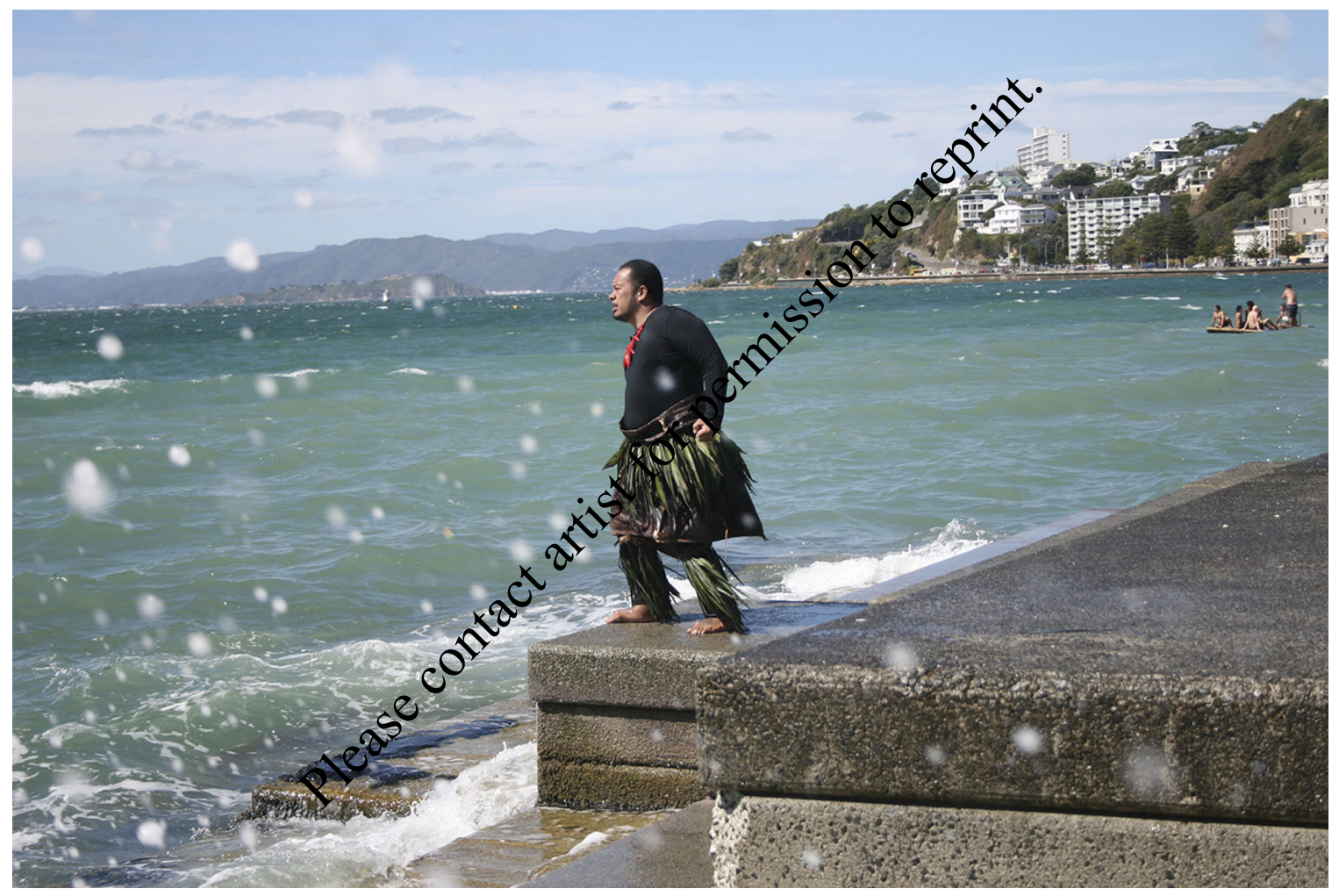

Ongo mei Moana, by Kalisolaite 'Uhila, 2015.

Performance, The Performance Arcade, Wellington.

Photo courtesy of the artist and Michael Lett.

For six hours each day-from low to high tide-for five days, 'Uhila undertook performances "conducting" the ocean with movement and oration in Wellington Harbor's Oriental Bay during the city's 20 I 5 Performance Arcade. Moana as ocean that connects Pacific Islanders with shared genealogies, stories, and histories of migration has been the site of regular maritime voyages and ongoing connections to other islands for 'Uhila's Tongan family. Exemplifying the convergence of living traditions and the spatiotemporal thinking that informs Epeli Hau'ofa's “Our Sea of Islands," Ongo mei Moana takes audiences to the ocean, heightening our sensitivity to its rhythms, flows, and unstoppable power. 


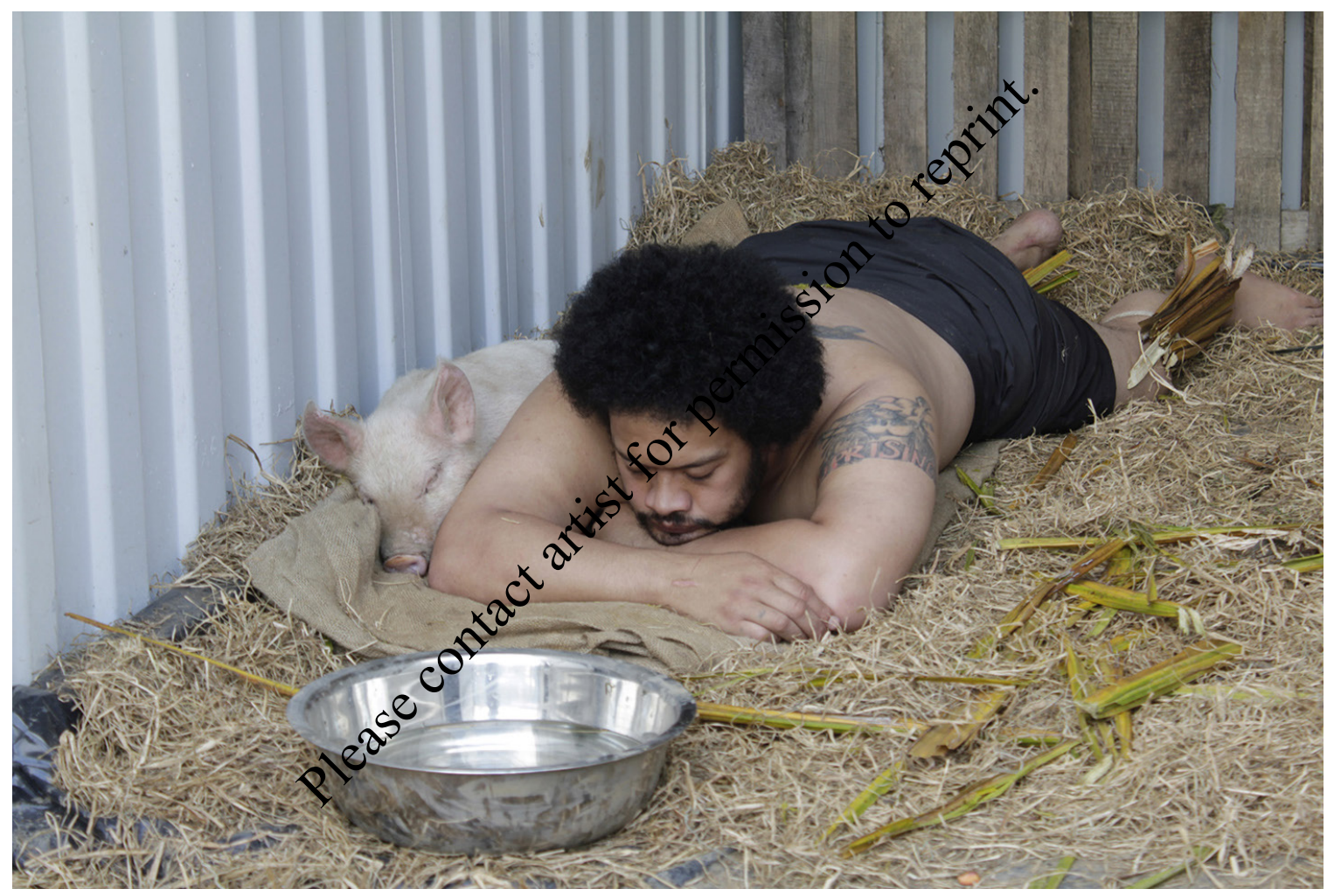

Pigs in the Yard, by Kalisolaite 'Uhila, 20I I.

Performance, Aotea Square Performance Arcade, Auckland.

Photo courtesy of the artist and Michael Lett.

In $20 \mathrm{II}$, 'Uhila lived with a piglet called Colonist for eight days in a shipping container in central Auckland's Aotea Square, in full view of passersby and much to the amusement of audiences who have followed his work ever since. Pigs are valued commodities and symbols of status and prestige in numerous Pacific Island cultures, including in Tonga, where they can be gifted and eaten on special occasions and wander for much of the time in relative freedom. Evaluated in the wake of 2010 Tongan constitutional reforms, Pigs in the Yard also heeds a call for greater transparency and ongoing debate, if balancing Tongan values and systems of authority with inherited British legal conventions is to improve conditions for Tongan citizens. 


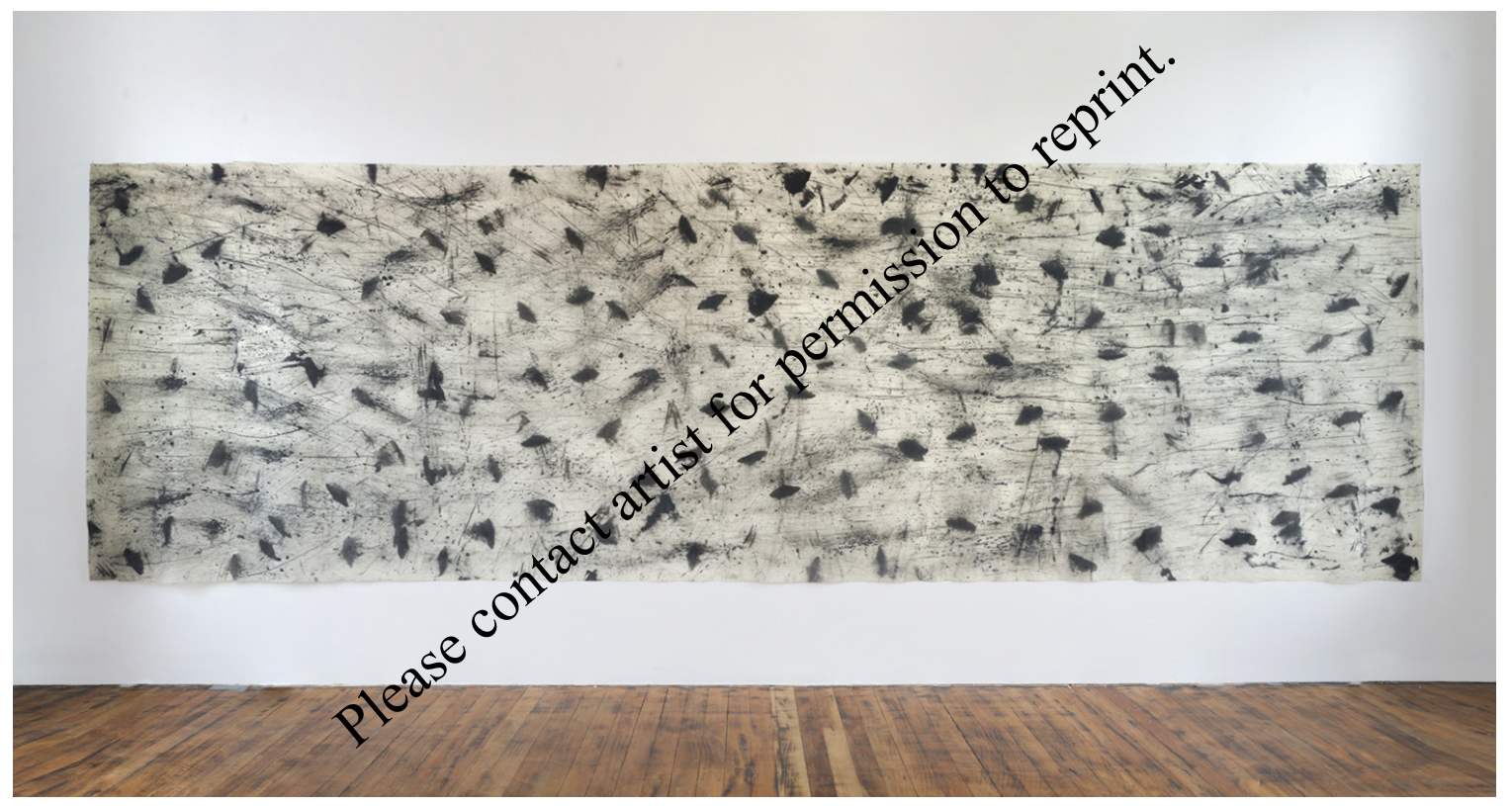

Fakama'a (III) (to make clean, to cleanse), by Kalisolaite 'Uhila, 20 I6.

Indian ink, acrylic paint, spunbonded polypropylene (pepa matolu), $6000 \times$ I $800 \mathrm{~mm}$.

Photo courtesy of the artist and Michael Lett.

Fakama'a (III) is one of a series of works made in 2016 that revisits ideas behind a much earlier performance piece that sparked 'Uhila's transition from visual artist to performance artist while an undergraduate printmaker at AUT. For that work, ink and acrylic were splattered and drawn across canvas as he attacked it with a machete, and for the later series on pepa matolu, rakes and other garden implements enhanced the diversity of mark-making tools used to trace patterns of body movement across the surface of his own very contemporary ngatu (Tongan decorated bark cloth). In what could be interpreted as a nod to the gestural abstraction and "action painting" of the American modernist painter Jackson Pollock, Fakama'a (III) makes more specific reference to individual and collective expressions of labor and the action of tools working the land, defining performance space through ritual and repetition, performing within rituals of display to mark transitions from one state to another, and establishing connections between customary and contemporary cultural practices for contemporary Pasifika artists. 


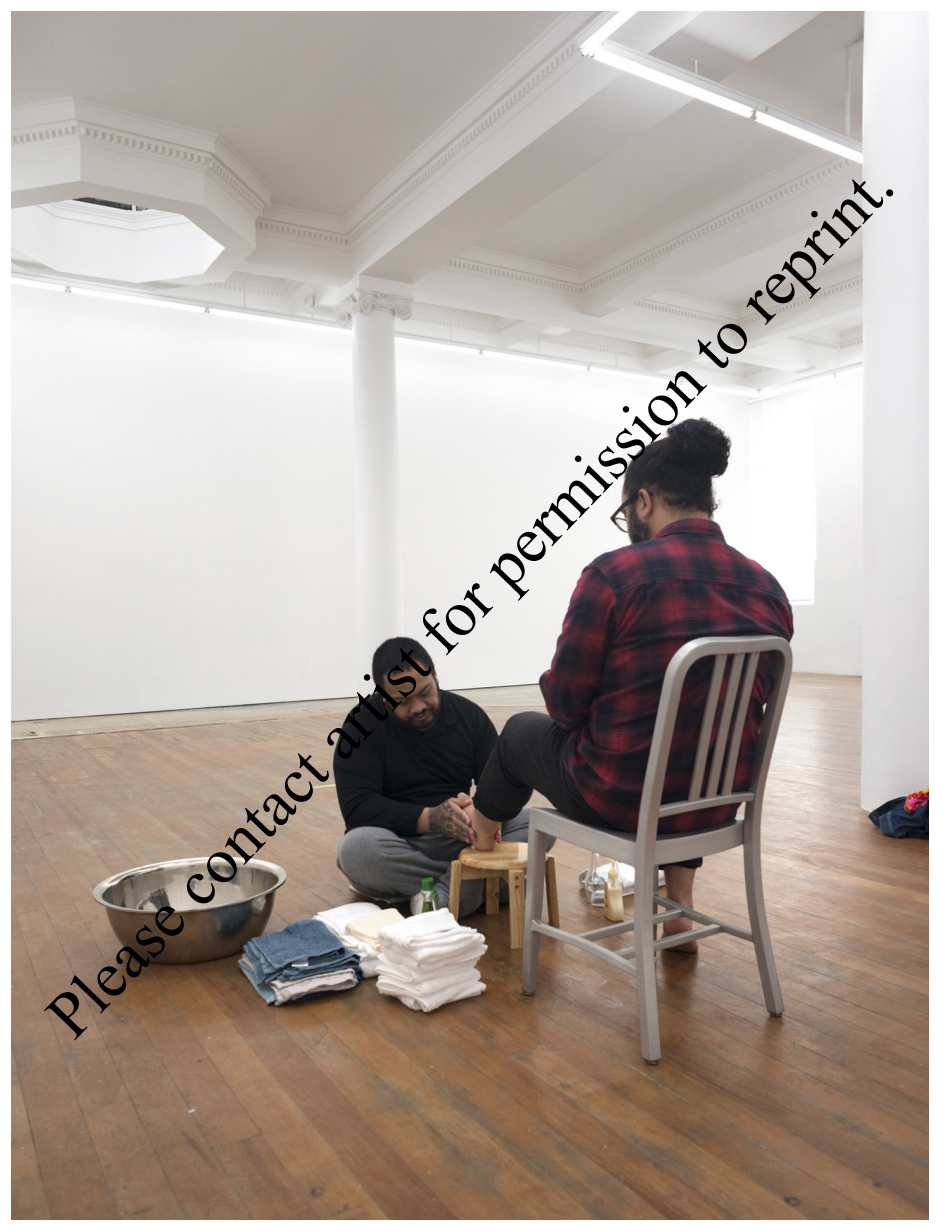

The first will be last and the last, first, by Kalisolaite 'Uhila, 2018 .

Performance, Michael Lett Gallery, Auckland, I I August-I September 20 I8. Photo courtesy of the artist and Michael Lett.

Within the title for 'Uhila's latest performance work for Michael Lett Gallery, audience members familiar with the New Testament may recognize a reference to teachings with messages of caution and humility, including how salvation is not necessarily determined by one's wealth or status in life. For 'Uhila, the gentle washing of feet symbolizes "the act of being of service" to others that gives purpose to his Christian faith, his life, and his creative practice. He also describes his performance work as providing opportunities to connect with his audience. On this occasion, the gallery was mesmerizingly quiet at first, and, as my turn approached, we exchanged breath and pressed noses in a hongi (Māori greeting) and paused to remember the last time we had seen one another. I sensed the audience relax as the sound of conversation grew out of silence, and as they too connected with one another. 